\title{
BMJ Open Spatial variations and associated factors of modern contraceptive use in Ethiopia: a spatial and multilevel analysis
}

\author{
Teketo Kassaw Tegegne (1) , ${ }^{1,2}$ Catherine Chojenta, ${ }^{2}$ Peta Michelle Forder, ${ }^{2}$ \\ Theodros Getachew, ${ }^{3}$ Roger Smith, ${ }^{2}$ Deborah Loxton ${ }^{2}$
}

To cite: Tegegne TK, Chojenta C, Forder PM, et al. Spatial variations and associated factors of modern contraceptive use in Ethiopia: a spatial and multilevel analysis. BMJ Open 2020;10:e037532. doi:10.1136/ bmjopen-2020-037532

- Prepublication history for this paper is available online. To view these files, please visit the journal online (http://dx.doi org/10.1136/bmjopen-2020037532).

Received 07 February 2020 Revised 29 July 2020 Accepted 13 August 2020

Check for updates

(C) Author(s) (or their employer(s)) 2020. Re-use permitted under CC BY-NC. No commercial re-use. See rights and permissions. Published by BMJ.

${ }^{1}$ Public Health, Debre Markos University, Debre Markos, Amhara, Ethiopia

${ }^{2}$ School of Medicine and Public Health, The University of Newcastle, Callaghan, New South Wales, Australia ${ }^{3}$ Health System and Reproductive Health Research Directorate, Ethiopian Public Health Institute, Addis Ababa, Ethiopia

Correspondence to Teketo Kassaw Tegegne; kteketo@yahoo.com

\section{ABSTRACT}

Objective To assess spatial variations in modern contraceptive use and to identify factors associated with it among married women in Ethiopia.

Design Cross-sectional analysis of population-based and health facility data.

Setting Ethiopia Demographic and Health Survey data linked to Service Provision Assessment data.

Population 8473 married women and 1020 facilities that reported providing family planning services.

Methods A linked secondary data analysis of population and health facility data was carried out. Both multilevel and spatial analyses were conducted to identify key determinants of women's use of modern contraceptive and spatial clustering of modern contraceptive use.

Main outcome measure Modern contraceptive use. Results About $24 \%$ of the variation in the use of modern contraception was accounted for by location. A one-unit increase in the mean score of health facilities' readiness to provide short-term modern contraceptives in a typical region was associated with a 20 -fold increase in the odds of modern contraceptive use (adjusted OR (AOR) 20.49, $95 \% \mathrm{Cl} 1.44$ to 29.54 ). In the spatial analysis, it was found that Addis Ababa and the Amhara region had high clusters of modern contraceptive use rates. On the other hand, low rates of contraceptive use were clustered in the Afar and Somali regions.

Conclusion There were significant variations in the use of modern contraceptives across the different regions of Ethiopia. Therefore, regions with low contraceptive rates and high fertility rates should be targeted for scaling up and tailoring of services to the culture and lifestyles of the population of those regions.

\section{INTRODUCTION}

Worldwide, modern contraceptives are important in fertility control. ${ }^{1}$ In developing countries, contraceptives have a clear effect on the health of women, children and families. For instance, contraceptives are estimated to prevent 2.7 million infant deaths and the loss of 60 million healthy lives a year worldwide. ${ }^{2}$ In countries with high fertility rates, promoting contraceptives averts $32 \%$ of all maternal deaths and approximately $10 \%$ of child mortality. Modern contraceptives

\section{Strengths and limitations of this study}

- This study identified both the demand and supplyside determinants of modern contraceptive utilisation using a linked population and health facility data.

- In addition to multilevel analysis, this study used spatial analyses to identify geographic variations of modern contraceptive utilisation

- This study excluded Demographic and Health Survey (DHS) clusters without geographic coordinates and used sampled health facilities that might underestimate or overestimate the study finding.

- This study did not consider sampling weights while running the multilevel analysis.

- DHS surveys provide an average weight (hv005 or v005); however, the GLIMMIX procedure in SAS requires weights at each level that did not enable to apply sampling weights in the multilevel analysis.

also make a huge contribution to the achievement of universal primary schooling, female empowerment, and in reducing poverty and hunger. ${ }^{3}$ Family planning is also important in preventing unintended pregnancies and unsafe abortions. $^{45}$

Despite its importance, access to and utilisation of modern contraceptives vary worldwide. Women in developed countries have better access to and use of contraceptives compared with women in developing countries. ${ }^{4}$ In a study from 2010 to 2014, it was reported that the global burden of unintended pregnancies was $44 \%$; the rate of unintended pregnancies is substantially higher in developing countries compared with developed regions. ${ }^{6}$ Higher levels of unmet need for contraception could contribute to higher rates of unintended pregnancies in developing regions. For instance, in sub-Saharan Africa, the prevalence of contraceptive use among women of reproductive age is only $17 \%{ }^{7}$

Similarly, the utilisation of modern contraceptives is a common healthcare challenge in Ethiopia. Even though there is an increase 
in women's use of modern contraceptives, challenges remain. ${ }^{8}$ Discrepancies in the use of modern contraceptives are common within the different parts of the country. For instance, the Somali region accounts for the lowest rate of modern contraceptive use (1.4\%), compared with Addis Ababa $(50.1 \%){ }^{8}$

The utilisation of modern contraceptives can be influenced by both demand-side and supply-side factors. In previous studies, more emphasis has been given to the importance of demand-side factors. ${ }^{7}$ Most of the investigated demand-side factors were women's education, ${ }^{79}$ age, ${ }^{910}$ household wealth ${ }^{7911}$ and parity. ${ }^{12} 13$ The importance of supply-side factors has been largely overlooked. In some studies, it was reported that the supply-side factors have influence on contraceptive use. For instance, the quality of family planning services ${ }^{14}$ and living close to a family planning facility ${ }^{15}$ were significantly associated with modern contraceptive utilisation. In East Africa, it was observed that the utilisation of modern contraceptives was higher among facilities providing different contraceptive methods and with higher family planning service environment scores. ${ }^{16}$

Due to the increasing availability of geographically referenced health facility and population data, it is possible to do geographically linked analyses. ${ }^{17}$ This opportunity allows identification of the location of existing health facilities as well as mapping the eligible population without access to a particular health service, such as family planning. This further enables identification of both the demand-side and supply-side factors and helps the government determine where future investments should be targeted.

This study aimed to assess spatial variations in the use of modern contraceptives among married women in Ethiopia and identify the potential factors associated with the use of modern contraceptives among married women throughout the country, using the national population and health facility data. Contraception is more critical for women of reproductive age. However, married women or women in union are more likely to be sexually active as opposed to single, divorced or widowed women, particularly in Ethiopia where sex outside of a union is uncommon. Therefore, this study focused on only married women's modern contraceptive use.

\section{METHODS}

\section{Data sources}

The main data sources of this study were the 2016 Ethiopia Demographic and Health Survey (EDHS) and the 2014 Ethiopian Service Provision Assessment Plus (ESPA+). Ethical approval was obtained from the DHS programme Institutional Review Board and the Ethiopian Public Health Institute.

The 2016 EDHS collected information on population characteristics, such as contraception and obstetric care use. The survey details can be found elsewhere. ${ }^{817}$ The geographic coordinates of each survey cluster were also collected. ${ }^{18}$ In the population survey, all women aged 15-49 years were eligible for individual interviews. The survey identified 16583 eligible women. Of these women, from 645 DHS clusters, 15683 were interviewed.

Contraception is more critical for women of reproductive age. However, married women or women in union are more likely to be sexually active as opposed to single, divorced or widowed women, particularly in Ethiopia where sex outside of a union is uncommon. Therefore, this study focused on only married women's modern contraceptive use. In this analysis, 8473 married women who were not pregnant at the time of the interview were included from 622 DHS clusters. A total of 261 married, non-pregnant women from 23 clusters were excluded from the analysis since they had missing geographic coordinates.

The main source of the health facility data was the 2014 ESPA+ survey. ${ }^{19}$ The ESPA+ survey had information on service availability and readiness, including family planning services. ${ }^{19}$ Details of the survey can be found elsewhere. ${ }^{17} 19$ The ESPA+ survey collected data from 1165 facilities. The survey used a combination of a census of hospitals and a sample of other health facilities (health centres, health posts and clinics). Of the 1165 facilities, 1020 facilities reported providing family planning services. In this analysis, 1020 facilities that reported providing family planning services were included.

\section{Data linking method}

In this study, we used an administrative boundary link for linking health facility data with the population data. ${ }^{17}$ Details of this method can be found elsewhere ${ }^{17}$ Ethiopia's administrative boundaries, used in this study, were obtained from Natural Earth. ${ }^{20}$

\section{Health service environment}

Four health service environment variable scores were created (average distance to the nearest family planning facility, family planning service availability, readiness to provide family planning services and general health facility readiness). All service availability and readiness scores were computed for the nearest family planning providing facilities. Details of this computation can be found elsewhere. ${ }^{17}$ Average straight-line distance to the nearest family planning providing facility was calculated after linking each DHS cluster with an ESPA+ survey facility. ${ }^{17}$ First, the distance from each cluster to every family planning providing facility within the administrative boundaries was calculated. Second, the nearest family planning providing facility was identified, and the average distance was computed per region.

In terms of the general service readiness score, eight general service readiness dimensions were obtained using principal component analysis. ${ }^{17}$ The average general service readiness score per region/city administration was computed using the SAS SCORE procedure. The first two principal components were used to compute two general service readiness scores (health 
facility management system and infrastructure). Further, indices of family planning availability and readiness were computed. Two family planning availability scores (long-acting and short-term contraceptive methods) were created using seven variables. ${ }^{17}$ Two family planning readiness scores (readiness to provide long-acting and short-term contraceptives) were created using seven variables. ${ }^{17}$

\section{Outcome and explanatory variables Explanatory variables}

The explanatory variables of this study were sociodemographic $^{7-11}$ and obstetric characteristics ${ }^{11-13}$ and health facility variables. ${ }^{11}{ }^{14-16}$ The sociodemographic characteristics include age, education, occupation, husband/ partner education and occupation, wealth, place of residence, and average distance to the nearest family planning facility. The obstetric characteristics were parity, the number of living children, ever use of modern contraception and exposure to family planning messages. Further, the health facility variables were general service readiness, family planning service availability and family planning service readiness.

The occupational status of respondents was grouped into four categories: have no work, agricultural work, professional/technical/managerial work and others. This was done based on the DHS occupation grouping. Respondents who responded not working at the time of the interview or did not work in the last 12 months before the survey were grouped as have no work. Professional/ technical/managerial category constitutes teaching professionals, health professionals, business and administration professionals, legal and social workers, managers and so on. Agricultural categories also include fishermen, foresters and hunters. Other categories include daily labourers, street and related sales and service workers.

\section{Exposure to family planning messages was measured based on three DHS questions}

The DHS collected data on woman's exposure to family planning messages whether the respondent has heard about family planning in the last few months (preceding the survey) from any of the following sources: (1) heard family planning on the radio last months, (2) heard family planning on TV last months and (3) heard family planning from the newspaper last months. In this paper, exposure to the contraceptive message was measured if the respondent had exposure to one or more information sources.

\section{Outcome variable}

The outcome variable of this study was modern contraceptive use. A woman was considered to be using modern contraception if she used any of the modern contraceptive methods other than male condoms. ${ }^{17}$ The male condom could be accessed from shops that the ESPA+ survey did not capture.

\section{Statistical analysis}

\section{Multilevel analysis}

To account for the nested nature of DHS data, a two-level generalised linear mixed model was used. This study had binary outcomes: whether a married woman used modern contraception or not. We were interested in the probability of modern contraceptive utilisation and the influence of individual and regional characteristics. The equation used to estimate the two-level hierarchical model can be found elsewhere. ${ }^{17}$

Binary distribution with the logit link function was used to model this binary outcome. To estimate this model, the GLIMMIX procedure in SAS was used. ${ }^{21}$ Four model building processes were undertaken. The Laplace estimation was used for estimating these models. The model building process began with an empty model. By checking improvements in model fit, complex models were built step by step. The random effects were measured by the intraclass correlation coefficient (ICC) and proportional change in variance (PCV). The variance estimate from each successive model was used to calculate the ICC. ${ }^{21}$ Details of calculating ICC in hierarchical generalised linear models can be found elsewhere. ${ }^{17} 22$ The PCV was used to measure the change in the area level variance between the empty model and the individual level model, and between successive models. ${ }^{23}{ }^{24}$ It was calculated using this mathematical equation: $P C V=\frac{V_{n-1}-V_{n-2}}{V_{n-1}}$ ; where $V_{n-1}$ is the neighbourhood variance in the empty model and $\mathrm{V}_{\mathrm{n}-2}$ is the neighbourhood variance in the subsequent model.

\section{Model fit statistics}

The Akaike Information Criteria (AIC) and Schwarz's Bayesian Information Criteria (BIC) were used to assess the best-fitting model. ${ }^{21}$ The AIC and BIC values of each successive model were compared, and the model with the lowest value was considered as the best-fitting model. ${ }^{25} 26$ During model building process, it is possible to increase the likelihood of fitting models by adding parameters. However, increasing model parameters can result in overfitting. Unlike statistical methods that employ hypothesis testing approaches like log-likelihood ratio test, AIC and BIC penalise the deviance for a larger number of parameters. ${ }^{26-28}$ Thus, they prevent overfitting by introducing a penalty term for the number of parameters in the model.

\section{Spatial analysis}

ArcGIS V.10.6.1 was used to do spatial analyses. The Ethiopian Polyconic Projected Coordinate System ${ }^{17}$ was used to flatten the Ethiopian map. Hot spot analysis was carried out to identify spatial clusters of modern contraceptive use. DHS clusters were the unit of spatial analyses.

We followed three analyses procedures while doing the hot spot analysis, as discussed elsewhere. ${ }^{17}$ First, we ran the Global Moran's I statistic, which is a global measure of spatial autocorrelation..$^{29}$ Second, based on the Global Moran's I statistic, incremental spatial autocorrelation was run to determine the critical distance at which clustering 
of modern contraception prevalence rate (mCPR) peaked $(165 \mathrm{~km}) .{ }^{17}$ Last, the Getis-Ord Gi* statistic was run to identify statistically significant spatial clusters of $\mathrm{mCPR} .{ }^{17}$ The two statistical problems of local statistics of spatial association (multiple comparison and spatial dependence) were controlled using an FDR correction. ${ }^{1730}$

\section{Patient and public involvement}

This study used secondary data sets: 2016 EDHS and 2014 ESPA+ that were previously collected with confidentiality information maintained (no personal identifier used). The data were collected under the collaboration of The Ethiopian Federal Ministry of Health, Ethiopian Central Statistical Agency, Ethiopian Public Health Institute and USAID. Hence, as we did not collect the data directly from participants, no recruitment and contact of participants were required for this analysis.

\section{RESULTS}

\section{Sociodemographic characteristics}

The mean age of the study participants was 31.09 (SD of \pm 8.22 ) years. Regarding education, $57.46 \%$ of the women had no formal education, while $27.58 \%$ had primary level education. In terms of wealth, $29.26 \%$ of the women fell in the richest quintile and $27.86 \%$ were grouped in the poorest quintile. Regarding religion, $38.27 \%$ of respondents identified as Orthodox Christian and $41 \%$ as Muslim. Seventy-three per cent of the respondents were from rural areas (see table 1 ).

\section{Women's obstetric characteristics}

Of the 8473 married women, 7721 (91.12\%) had ever given birth. The mean age at first childbirth was 18.98 (SD of \pm 3.85 ) years. In terms of parity, $37.11 \%$ of married women had five or more births; $31.05 \%$ of the women had more than four living children. Among the 5708 women who were pregnant in the previous 5 years, 1853 (32.46\%) had no antenatal care visits for their most recent pregnancy. There were $19.40 \%$ of women who reported they had the autonomy to decide on their own healthcare needs. Under one-third (31.24\%) of women had been exposed to family planning messages. More than half $(52.79 \%)$ of married women had ever used contraceptive methods. Of the 8473 married women, 5519 (65.14\%) were not using any contraceptive methods at the time of the survey. Among these women, 1957 (35.46\%) had a future intention to use contraception (see table 2).

\section{Health facility characteristics}

Data were collected from 1165 health facilities nationwide. Among them, $18.73 \%$ were hospitals and $27.75 \%$ were health centres. Regarding health facility managing body, $68.43 \%$ of the health facilities were managed by the government. Of the facilities, $1020(87.55 \%)$ provided family planning services. Three-quarters $(75.2 \%)$ had a contraceptive method mix; they provided three or more contraceptive methods. In terms of modern contraceptive
Table 1 Sociodemographic characteristics of married women in Ethiopia, $2016(\mathrm{~N}=8473)$

\begin{tabular}{|c|c|c|}
\hline Variable & Frequency & Percentage \\
\hline \multicolumn{3}{|l|}{ Age (years) } \\
\hline $15-19$ & 534 & 6.30 \\
\hline $20-24$ & 1436 & 16.95 \\
\hline $25-29$ & 1876 & 22.14 \\
\hline $30-34$ & 1591 & 18.78 \\
\hline $35-39$ & 1412 & 16.66 \\
\hline $40-44$ & 953 & 11.25 \\
\hline $45-49$ & 671 & 7.92 \\
\hline \multicolumn{3}{|l|}{ Level of education } \\
\hline No education & 4869 & 57.46 \\
\hline Primary & 2337 & 27.58 \\
\hline Secondary & 773 & 9.12 \\
\hline Higher & 494 & 5.83 \\
\hline \multicolumn{3}{|l|}{ Occupation } \\
\hline Have no work & 6030 & 71.17 \\
\hline $\begin{array}{l}\text { Professional/technical/managerial } \\
\text { work }\end{array}$ & 1310 & 15.46 \\
\hline Agricultural work & 749 & 8.84 \\
\hline Other & 384 & 4.53 \\
\hline \multicolumn{3}{|l|}{ Husband/partner's level of education } \\
\hline No education & 3774 & 44.54 \\
\hline Primary & 2651 & 31.29 \\
\hline Secondary & 1060 & 12.51 \\
\hline Higher & 988 & 11.66 \\
\hline \multicolumn{3}{|l|}{ Husband/partner's occupation } \\
\hline Have no work & 851 & 10.04 \\
\hline $\begin{array}{l}\text { Professional/technical/managerial } \\
\text { work }\end{array}$ & 2592 & 30.59 \\
\hline Agricultural work & 4208 & 49.66 \\
\hline Other & 822 & 9.70 \\
\hline \multicolumn{3}{|l|}{ Head of household* } \\
\hline Someone else & 7147 & 84.35 \\
\hline Woman-herself & 1326 & 15.65 \\
\hline \multicolumn{3}{|l|}{ Family size } \\
\hline $1-4$ & 3050 & 36.00 \\
\hline $5-8$ & 4564 & 53.86 \\
\hline$\geq 9$ & 859 & 10.14 \\
\hline \multicolumn{3}{|l|}{ Wealth quintile } \\
\hline Lowest & 2361 & 27.86 \\
\hline Second & 1291 & 15.24 \\
\hline Middle & 1184 & 13.97 \\
\hline Fourth & 1158 & 13.67 \\
\hline Highest & 2479 & 29.26 \\
\hline \multicolumn{3}{|l|}{ Religion } \\
\hline Orthodox & 3243 & 38.27 \\
\hline Protestant & 1597 & 18.85 \\
\hline Muslim & 3474 & 41.00 \\
\hline
\end{tabular}

Continued 


\begin{tabular}{ccc}
\hline Table 1 & Continued & \\
\hline Variable & Frequency & Percentage \\
\hline Other & 159 & 1.88 \\
Residence & & \\
Urban & 2261 & 26.68 \\
Rural & 6212 & 73.32 \\
\hline
\end{tabular}

*The head of household was dichotomised as the woman herself or someone else (this include her husband and other family members, such as father-in-law and mother-in-law).

method types, $53.73 \%$ of the health facilities provided long-acting contraceptives, while $99.31 \%$ provided short-term contraceptive methods. The national average distance from family planning health facilities to the 2016 EDHS clusters was $6.35 \mathrm{~km}$. The 2016 EDHS-sampled clusters in the Somali region were the longest distance $(18.58 \mathrm{~km})$ from family planning facilities. Conversely, EDHS clusters in Addis Ababa were $0.55 \mathrm{~km}$ from family planning facilities (see table 3 ).

\section{Modern contraceptive prevalence rate}

The prevalence of modern contraceptive use among married women was found to be $33.54 \%$ (urban $46.09 \%$, $28.98 \%$ rural). The utilisation of modern contraceptives varied across the different regions and city administrations; the highest mCPR was reported in the Amhara region $(51.65 \%)$, followed by Addis Ababa (50.08\%) and the Southern Nations, Nationalities and Peoples Region (SNNPR) (45.48\%). Figure 1 shows the regional variations in mCPRs.

\section{Spatial epidemiology of modern contraceptive use}

There is strong evidence to support spatial clustering in the utilisation of modern contraceptives among married women in Ethiopia (Global Moran's I=0.24; Z-score=8.09; $\mathrm{p}<0.0001)$. Most of the hot spot areas, those with high contraceptive prevalence rates, were located in Addis Ababa and Amhara, followed by the Oromia region and the SNNPR. Conversely, the majority of the cold spot areas, those with low contraceptive prevalence rates, were located in the Somali, Afar and Gambela regions followed by Tigray and Benishangul-Gumuz. This clustering was supported by the $G i^{*}$ statistic when conducting the spatial analysis (see figure 2).

\section{Determinants of modern contraceptive use among married women}

The calculated ICC was $24.47 \%$. This indicated that about $24 \%$ of the variability in using modern contraceptive methods was accounted for by location, leaving $76 \%$ of the variability to be accounted for by the differing characteristics of the women, or other unmeasured factors. The probability of using modern contraceptive methods in a typical region was estimated at $27.8 \%$.

The strong individual-level predictors of modern contraceptive use among married women were their age,
Table 2 Obstetric characteristics of married women in Ethiopia, $2016(\mathrm{~N}=8473)$

\begin{tabular}{|c|c|c|}
\hline Variable & Frequency & Percentage \\
\hline \multicolumn{3}{|l|}{ Parity } \\
\hline 0 & 752 & 8.88 \\
\hline $1-4$ & 4577 & 54.02 \\
\hline$\geq 5$ & 3144 & 37.11 \\
\hline \multicolumn{3}{|l|}{ No of living children } \\
\hline 0 & 813 & 9.60 \\
\hline $1-4$ & 5029 & 59.35 \\
\hline$\geq 5$ & 2631 & 31.05 \\
\hline \multicolumn{3}{|c|}{ Age at first childbirth $(n=7721)$} \\
\hline$\leq 19$ years & 5618 & 66.30 \\
\hline 20-24 years & 2224 & 26.25 \\
\hline$\geq 25$ years & 631 & 7.45 \\
\hline \multicolumn{3}{|l|}{ No of ANC visits $(n=5708)$} \\
\hline 0 & 1853 & 32.46 \\
\hline $1-3$ & 1688 & 29.57 \\
\hline$\geq 4$ & 2167 & 37.96 \\
\hline \multicolumn{3}{|c|}{ Autonomy in personal healthcare decision-making } \\
\hline Respondent alone & 1644 & 19.40 \\
\hline Joint decision & 5298 & 62.53 \\
\hline Husband/partner alone & 1531 & 18.07 \\
\hline \multicolumn{3}{|c|}{ Autonomy in family planning decision-making $(n=2954)$} \\
\hline Mainly respondent & 724 & 24.51 \\
\hline Mainly husband/partner & 149 & 5.04 \\
\hline Joint decision & 2081 & 70.45 \\
\hline \multicolumn{3}{|c|}{ Knowledge of modern contraceptive methods } \\
\hline No & 324 & 3.82 \\
\hline Yes & 8149 & 96.18 \\
\hline \multicolumn{3}{|c|}{ Exposure to family planning messages } \\
\hline No & 5826 & 68.76 \\
\hline Yes & 2647 & 31.24 \\
\hline \multicolumn{3}{|c|}{ Ever used any contraceptive method } \\
\hline No & 4000 & 47.21 \\
\hline Yes & 4473 & 52.79 \\
\hline
\end{tabular}

Non-users' future intention to use a contraceptive method $(\mathrm{n}=5519)$

\begin{tabular}{lrc} 
Intends to use later & 1957 & 35.46 \\
Unsure about future use & 90 & 1.63 \\
Does not intend to use & 3472 & 62.91 \\
\hline
\end{tabular}

ANC, antenatal care.

their husband/partner's education, household wealth, number of living children and exposure to family planning messages. Women who were in the age groups $35-39$ years $(44 \%), 40-44$ years $(55 \%)$ and $45-49$ years $(82 \%)$ were less likely to use modern contraceptives compared with those aged 15-19years. A woman whose husband attained a primary level of education was $54 \%$ 
Table 3 Average distance from sampled family planning providing health facilities to demographic and health survey clusters in Ethiopia, $2016(\mathrm{~N}=1020)$

\begin{tabular}{|c|c|c|c|c|c|c|}
\hline \multirow[b]{2}{*}{ Region } & \multirow{2}{*}{$\begin{array}{l}\text { Population } \\
\text { projection for } 2016 \\
\text { (in thousands) }^{\star}\end{array}$} & \multicolumn{4}{|c|}{ Health facility type } & \multirow{2}{*}{$\begin{array}{l}\text { Average } \\
\text { distance } \\
(\mathrm{km})\end{array}$} \\
\hline & & $\begin{array}{l}\text { Hospitals } \\
\text { n (\%) }\end{array}$ & $\begin{array}{l}\text { Health centres } \\
\mathrm{n}(\%)\end{array}$ & $\begin{array}{l}\text { Health posts } \\
\text { n (\%) }\end{array}$ & $\begin{array}{l}\text { Private clinics } \\
\text { n (\%) }\end{array}$ & \\
\hline Tigray & 5151 & $30(28.30)$ & $30(28.30)$ & $25(23.58)$ & $21(19.81)$ & 5.53 \\
\hline Afar & 1768 & $6(10.71)$ & 25 (44.64) & $16(28.57)$ & $9(16.07)$ & 9.69 \\
\hline Amhara & 20771 & $26(16.77)$ & 46 (29.68) & $34(21.94)$ & 49 (31.61) & 8.47 \\
\hline Oromia & 34575 & 49 (25.26) & $50(25.77)$ & $43(22.16)$ & $52(26.80)$ & 8.99 \\
\hline Somali & 5599 & $10(20.41)$ & $21(42.86)$ & $12(24.49)$ & $6(12.24)$ & 18.58 \\
\hline Benishangul-Gumuz & 1035 & $2(3.13)$ & $16(25.00)$ & $29(45.31)$ & $17(26.56)$ & 5.28 \\
\hline SNNPR & 18720 & $24(15.58)$ & $40(25.97)$ & $38(24.68)$ & $52(33.77)$ & 7.08 \\
\hline Gambela & 422 & $1(1.79)$ & $14(25.00)$ & $22(39.29)$ & 19 (33.93) & 4.32 \\
\hline Harari & 238 & $4(9.30)$ & $8(18.60)$ & $21(48.84)$ & $10(23.26)$ & 0.73 \\
\hline Addis Ababa & 3353 & $33(42.31)$ & $18(23.08)$ & 0 & 27 (34.62) & 0.55 \\
\hline Dire Dawa & 453 & $6(9.23)$ & $15(23.08)$ & 31 (47.69) & $13(20.00)$ & 0.60 \\
\hline Total & 92085 & $191(18.73)$ & $283(27.75)$ & $271(26.57)$ & 275 (26.96) & 6.35 \\
\hline
\end{tabular}

${ }^{*}$ Central Statistical Agency-Population Projections for Ethiopia: 2007-2037.

SNNPR, Southern Nations, Nationalities and Peoples Region.

more likely to use modern contraceptives compared with those whose husband had no education. The OR of modern contraceptive use increased with increasing wealth quintile. Women who were in the highest quintile were 5.26 times more likely to use the service compared with those in the lowest quintile. Women who had been exposed to family planning messages were $68 \%$ more likely to use modern contraceptives relative to their counterparts with no exposure to family planning messages. Similarly, women who had one to four children were 2.31 times more likely to use the service compared with those having no child (see table 4).

At the regional level (level 2), only one variable was significantly associated with the use of modern contraceptives. A one-unit increase in the mean score of a

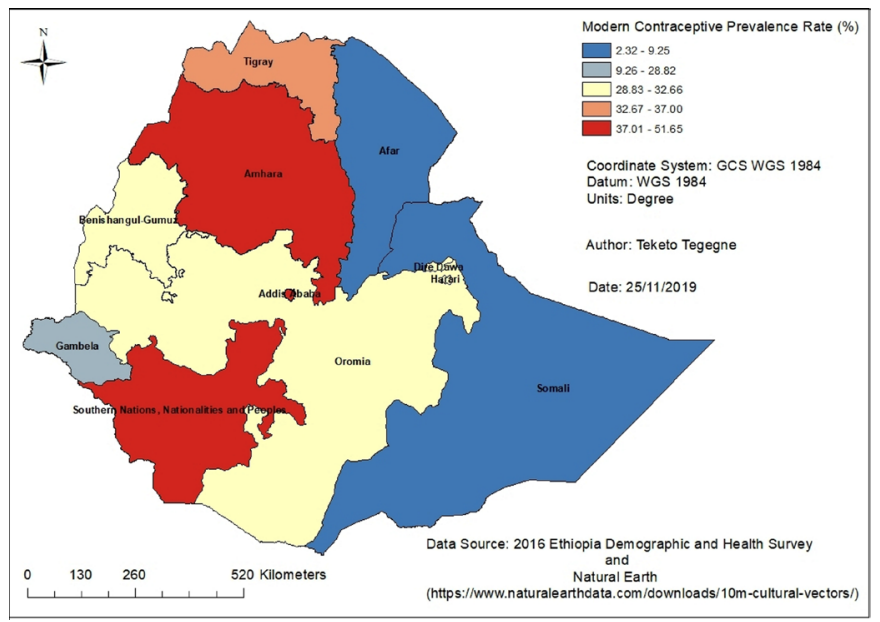

Figure 1 Modern contraceptive use among married women in Ethiopia, 2016. health facility's readiness to provide short-term modern contraceptives in a typical region was associated with a 20-fold increase in the odds of modern contraceptive use (table 4).

Finally, the majority of the variance between regions was explained by this model. The proportional change in variance indicated that the addition of predictors to the empty model explained an increased proportion of variation in modern contraceptive use. The variance estimates between regions decreased from 1.07 in the empty model to 0.18 in the final random intercept and random slope model. The proportion of variance explained by the final model was $83.51 \%$. Similarly, the empty model showed that $24.47 \%$ of the variability in the odds of modern contraceptive use was explained by region-level characteristics $(\mathrm{ICC}=\mathbf{2 4 . 4 7 \%})$. The between-region variability

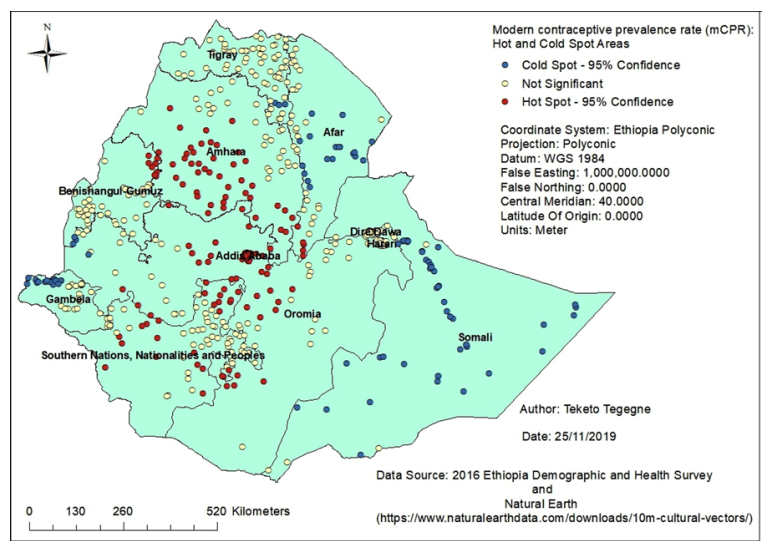

Figure 2 Clusters of high and low modern contraceptive prevalence rates in Ethiopia, 2016. 
Table 4 Factors associated with utilisation of modern contraceptives among married women in Ethiopia ( $\mathrm{N}=8473)$

\begin{tabular}{|c|c|c|c|}
\hline Predictors & $\begin{array}{l}\text { Model } 2^{*} \\
\text { AOR }(95 \% \mathrm{Cl})\end{array}$ & $\begin{array}{l}\text { Model 3† } \\
\text { AOR }(95 \% \mathrm{Cl})\end{array}$ & $\begin{array}{l}\text { Model } 4 \ddagger \\
\text { AOR }(95 \% \text { Cl) }\end{array}$ \\
\hline \multicolumn{4}{|l|}{ Level 1 predictor variables } \\
\hline \multicolumn{4}{|l|}{ Age (years) } \\
\hline $15-19$ & 1.00 & 1.00 & 1.00 \\
\hline $20-24$ & $1.21(0.94$ to 1.55$)$ & 1.27 (0.91 to 1.76$)$ & $1.26(0.91$ to 1.76$)$ \\
\hline $25-29$ & $0.92(0.71$ to 1.18$)$ & 0.94 (0.67 to 1.31$)$ & $0.93(0.67$ to 1.30$)$ \\
\hline $35-39$ & $0.60(0.45$ to 0.79$)$ & $0.56(0.40$ to 0.80$)$ & $0.56(0.39$ to 0.80$)$ \\
\hline $40-44$ & $0.50(0.37$ to 0.67$)$ & $0.45(0.31$ to 0.65$)$ & $0.45(0.31$ to 0.65$)$ \\
\hline $45-49$ & 0.20 (0.14 to 0.28$)$ & $0.18(0.12$ to 0.27$)$ & $0.18(0.12$ to 0.27$)$ \\
\hline \multicolumn{4}{|l|}{ Husband/partner's level of education } \\
\hline Higher & 0.88 (0.72 to 1.08$)$ & $1.06(0.77$ to 1.45$)$ & $1.05(0.77$ to 1.44$)$ \\
\hline \multicolumn{4}{|l|}{ Wealth quintile } \\
\hline Lowest & 1.00 & 1.00 & 1.00 \\
\hline Second & 1.96 (1.62 to 2.38$)$ & 1.96 (1.27 to 3.02$)$ & 1.95 (1.27 to 2.99$)$ \\
\hline Middle & 2.53 (2.09 to 3.07$)$ & 2.66 (1.72 to 4.13$)$ & 2.65 (1.72 to 4.08$)$ \\
\hline Fourth & 3.14 (2.58 to 3.82$)$ & 3.46 (2.23 to 5.37$)$ & $3.42(2.21$ to 5.28$)$ \\
\hline Highest & 5.09 (4.17 to 6.22$)$ & 5.45 (3.56 to 8.33$)$ & 5.26 (3.46 to 7.99$)$ \\
\hline \multicolumn{4}{|l|}{ No of living children } \\
\hline 0 & 1.00 & 1.00 & 1.00 \\
\hline $1-4$ & 2.04 (1.66 to 2.50$)$ & 2.31 (1.65 to 3.23$)$ & 2.31 (1.64 to 3.25$)$ \\
\hline \multicolumn{4}{|l|}{ General service readiness } \\
\hline Health facility management system & & & 1.27 (0.05 to 35.69$)$ \\
\hline Health facility infrastructure & & & 1.51 (0.18 to 12.95$)$ \\
\hline \multicolumn{4}{|l|}{ Family planning service availability } \\
\hline Long-acting contraceptive methods & & & 5.04 (0.19 to 136.21$)$ \\
\hline Short-term contraceptive methods & & & 1.79 (0.03 to 103.48$)$ \\
\hline \multicolumn{4}{|l|}{ Family planning service readiness } \\
\hline Long-acting contraceptives & & & 0.43 (0.01 to 17.12$)$ \\
\hline Short-term contraceptives & & & 20.49 (1.44 to 29.54$)$ \\
\hline Average distance to the nearest health facility & & & 1.02 (0.81 to 1.28$)$ \\
\hline
\end{tabular}

The bold values indicate a statistically significant association at a $95 \%$ confidence interval. *Model 2 is adjusted for individual-level factors.

†Model 3 is random slope and random intercept model adjusted for individual-level factors.

$\ddagger$ Model 4 is the final model adjusted for individual-level and region-level factors. N.B. Model 1 (empty model) is not included in this table (but is in table 5). 
Table 5 Variations in modern contraceptive use in Ethiopia: random slope and random intercept model

\begin{tabular}{|c|c|c|c|c|}
\hline $\begin{array}{l}\text { Random effects } \\
\text { (measure of variation for modern } \\
\text { contraceptive use) }\end{array}$ & Model 1* & Model $2 \dagger$ & Model 3‡ & Model 4§ \\
\hline Region-level variance (SE) & $1.07(0.47)$ & $0.90(0.47)$ & $0.84(0.38)$ & $0.18(0.16)$ \\
\hline$P$ value & $<0.05$ & $<0.05$ & $<0.05$ & $<0.05$ \\
\hline Variance in age (SE) & & & $0.04(0.02)$ & $0.05(0.02)$ \\
\hline$P$ value & & & $<0.05$ & $<0.05$ \\
\hline Variance in wealth quintile (SE) & & & $0.14(0.05)$ & $0.14(0.05)$ \\
\hline$P$ value & & & $<0.01$ & $<0.01$ \\
\hline $\begin{array}{l}\text { Variance in exposure to family } \\
\text { planning messages) (SE) }\end{array}$ & & & $0.08(0.05)$ & $0.09(0.06)$ \\
\hline$P$ value & & & $<0.05$ & $>0.05$ \\
\hline ICC (\%) & 24.47 & 21.47 & 20.43 & 5.07 \\
\hline Explained variance (PCV) (\%) & Reference & 15.61 & 20.74 & 83.51 \\
\hline \multicolumn{5}{|l|}{ Model fit statistics } \\
\hline $\mathrm{AIC}$ & 9959.57 & 9073.71 & 8920.49 & 8918.61 \\
\hline $\mathrm{BIC}$ & 9960.36 & 9080.87 & 8932.43 & 8927.76 \\
\hline
\end{tabular}

*Model 1 is the null model, a baseline model without any determinant variable.

†Model 2 is adjusted for individual-level factors.

¥Model 3 is random slope and random intercept model adjusted for individual-level factors.

$\S$ Model 4 is the final model adjusted for individual-level and region-level factors.

AIC, Akaike's Information Criterion; BIC, Schwarz's Bayesian Information Criterion; ICC, intraclass correlation coefficient; PCV, percentage change in variance.

declined over successive models, from $24.47 \%$ in the empty model to $5.07 \%$ in the final model (see table 5 ).

\section{DISCUSSION}

In Ethiopia, the use of modern contraception varied by region. This is the first study to specifically identify hot spots and model the use of modern contraception using nationwide population and health facility data. Approximately $34 \%$ of married women use modern contraceptives; the highest mCPR was reported among urban married women $(46.09 \%$ vs $28.98 \%)$. This is comparable with the findings of the 2011 EDHS data analysis where $27.3 \%$ of married women reported using modern contraceptive methods; the highest proportion was from urban areas $(49.55 \%$ vs $22.5 \%) .{ }^{9}$ There are also variations in modern contraceptive rate across different regions in the country. The highest contraceptive rate, more than $50 \%$ mCPR, was reported in the Amhara region and the Addis Ababa city administration. Conversely, the lowest, below $10 \%$ mCPR, was reported in the Somali and Afar regions. Even though there has been an increase in modern contraceptive use all over the country, it was found that there was significant regional variation in modern contraceptive use.

High mCPR spots (hot spots) were detected in the Amhara region and Addis Ababa, followed by the SNNPR and some parts of Oromia region. Conversely, the majority of low mCPR (cold spots) were detected in the Somali, Afar and Gambela regions followed by Tigray and Benishangul-Gumuz. In 2011, hot spots of modern contraceptive use were observed in Addis Ababa, followed by some parts of Amhara, Oromia and SNNPR. The lowest contraceptive rates (cold spots) were observed in the Afar, Somali and Gambela regions, and some parts of Tigray region. ${ }^{9}$ This indicated that the government is doing a good job in some of the regions, but is less successful in most regions. Due to this reason, the unmet need for modern contraception will be much higher than expected in most of those regions. Thus, cold spots (low rates of modern contraception) will be much more concentrated in those areas.

In Ethiopia, the use of modern contraceptives varied across the different regions and city administrations. The highest modern contraceptive prevalence rate 
was reported in the Amhara region, followed by Addis Ababa and SNNPR. This variation is demonstrated by the national DHSs conducted every 5 years since 2000 . Over 16 years, between 2000 and 2016, the Amhara region and SNNPR showed an increase in the utilisation of modern contraceptives. $^{8}{ }^{31-33}$ The large increase in the use of modern contraceptives in the Amhara region, as well as SNNPR, might be related to the high number of family planning organisations and the government's focus on these regions.

Different individual and regional factors were significantly associated with the use of modern contraceptives. The readiness of health facilities to provide short-term modern contraceptives was the only regional (level 2) variable that was significantly associated with the use of modern contraceptives. It was found that a one-unit increase in the mean score of the readiness of health facilities to provide short-term modern contraceptives was significantly associated with the utilisation of modern contraceptives. In a study that used DHS and SPA survey data from several East African countries (Kenya, Uganda, Rwanda and Tanzania), it was found that modern contraceptive utilisation was strongly associated with health facilities offering a wide range of contraceptives and with a higher score of family planning service environment. ${ }^{16}$ Even though it is not directly related, in a study carried out in rural Ethiopia, researchers found that women who lived close to a health facility providing a wide range of contraceptives were more likely to use modern contraceptives. ${ }^{11}$ This indicated that the potential impact of family planning services should not be underestimated. Therefore, family planning health facilities should be fully equipped to provide a wide range of modern contraception.

Among the individual factors, an increase in the age of women was significantly associated with a decrease in the use of modern contraceptives. This is similar to results of other studies carried out in Ethiopia, where the utilisation of modern contraceptives was negatively influenced by an increase in the age of women. ${ }^{911} 12$ This could be related to the knowledge gap, beliefs and/or attitudes that each woman has; as the age of a woman increases, the probability of changing her attitudes or beliefs towards contraception may reduce.

In Ethiopia, among the individual-level variables, the educational attainment of husband/partners was a significant predictor of the increase in modern contraceptive use. In a study conducted in the North Gondar, Amhara region of Ethiopia, it was found that the educational attainment of husbands was a significant predictor of women's contraceptive use. ${ }^{34}$ This might be due to the involvement of husbands in contraception decisionmaking. This is supported by other studies demonstrating the influence of discussing modern contraceptives with the husband and the husband's approval of using modern contraceptives. ${ }^{35}{ }^{36}$ It was found that the utilisation of modern contraceptives was significantly higher among women whose husbands had approved of using modern contraceptives. Similarly, the odds of using modern contraceptives was higher among those women who had discussed modern contraceptives with their husbands. ${ }^{35} 36$ This indicated that a woman's husband's education, as well as male involvement, has an important role in the use of modern contraceptives. Thus, educational opportunities for men and increasing male involvement in every family planning service should be emphasised for higher engagement in the use of modern contraception.

The increase in household wealth was a significant predictor of an increase in modern contraceptive utilisation. In two studies conducted in Ethiopia, including a study performed among rural women, ${ }^{11}$ it was found that women who were in the fourth and highest quintile were more likely to use modern contraceptives. ${ }^{911}$ Family monthly income was significantly associated with the use of modern contraceptives. ${ }^{35}$ Wealth might directly or indirectly affect modern contraceptive use. Women might know about the importance of contraception. However, knowledge alone will not be important in some cases. They should have money for transport and service. The trade-off associated with the time they spent on travelling to and from health facilities is also important. They may use that particular time for household activities, farming or other business-generating activities. For instance, in Ethiopia, despite family planning services being free of charge in public health facilities, the cost of transport might be attributable to the use of modern contraception. Moreover, the costs of family planning services in private health facilities might also be related to the use of modern contraceptives. Thus, the cost of transport and family planning service fees in private health facilities might not be important for wealthy families.

In this current study, it was found that, compared with having no children, having one or more living children increases the likelihood a woman will use modern contraceptives. In the 2011 EDHS data analysis ${ }^{9}$ and a study done in the SNNPR, ${ }^{12}$ researchers also found that an increase in the number of living children was significantly associated with an increase in modern contraceptive use. Among rural women in Ethiopia, an increase in parity was positively associated with an increase in modern contraceptive use. ${ }^{11}$ This finding is similar to studies done in Bangladesh, Pakistan and Tanzania, where it was reported that an increase in the number of living children was significantly associated with an increase in the use of modern contraceptives. ${ }^{133738}$ This indicated that women's desire to have children might influence their contraceptive use behaviours: women with a high number of living children may be more likely to use contraception.

Exposure to family planning messages, the last individual-level variable in the multilevel model, showed an increase in the likelihood of using modern contraception. In a study done among women of reproductive age in the SNNPR region, it was found that the odds of modern contraceptive utilisation were significantly associated with women's overall knowledge of family planning methods. It was observed that women with good family planning knowledge were more likely to use modern 
contraceptives. $^{12}$ Thus, exposure to family planning messages through different public and private media outlets is an important recommendation arising from this study.

In this study, it was found that the utilisation of modern contraceptives varied across regions. The individual-level variables (age, husband/partner's education, wealth, number of living children and exposure to family planning messages) varied significantly across the regions. In a study in rural Ethiopia, it was found that the use of modern contraceptives was significantly higher in the Amhara and SNNPR regions. ${ }^{11}$ This might be related to variations in the availability and accessibility of different family planning services across administrative regions of the country. In addition to the multilevel analysis, this study has identified the hot spot and cold spot areas to help the government in improving the provision of modern contraceptives, especially those areas with the low rates of modern contraception.

This study identified both the demand-side and supplyside determinants of modern contraceptive utilisation using a linked population and health facility data. This was overlooked in previous studies, which generally studied these factors separately. In addition to multilevel analysis, this study used spatial analyses to identify geographic variations in modern contraceptive utilisation. Taking a geographic perspective on family planning is very important for effective resource allocation and intervention, informed decision-making, and monitoring and evaluation purposes.

This study had several methodological limitations, most of which were minimised. ${ }^{17}$ The exclusion of DHS clusters without information relating to geographic coordinates, and using sampled health facilities, may underestimate or overestimate our study findings. This study did not consider sampling weights while running the multilevel analysis. DHSs provide an average weight (hv005 or v005); however, the GLIMMIX procedure in SAS requires weights at each level. Due to this issue, we could not able to apply sampling weights in the multilevel analysis.

\section{CONCLUSION}

In this study, it was found that more than one-third of married women in Ethiopia use modern contraceptives. It was also found that different individual-level variables, as well as regional-level variables, were predictors of modern contraceptive use. There is evidence of wide geographic variations in the use of modern contraceptives across the country. The findings of this study have several implications: first, regions with low contraceptive rates and high fertility rates should be targeted for scaling up and tailoring of services to the lifestyles of their populations. Second, available health facilities should be equipped to provide modern contraceptive methods. Strong emphasis should also be given to the contraceptive method mix/choice available at each health facility to increase contraceptive uptake. Third, increasing educational opportunities for men and increasing male involvement, and exposure to family planning messages are also important recommendations to arise from this research. The importance of awareness and the potential impact of services cannot be underestimated.

Acknowledgements We thank the University of Newcastle, Australia for offering free access to the digital online library to search the electronic databases that were considered for this analysis. We also thank the Measure DHS programme and the Ethiopian Public Health Institute for providing free access to the datasets used for this analysis.

Contributors TKT, CC, RS and DL conceptualised the design of the analysis. TKT developed and drafted the manuscript. CC, PMF, TG, RS and DL participated in critically revising the intellectual contents of the manuscript. All authors read, provided feedback and approved the final manuscript.

Funding The authors have not declared a specific grant for this research from any funding agency in the public, commercial or not-for-profit sectors.

Map disclaimer The depiction of boundaries on this map does not imply the expression of any opinion whatsoever on the part of BMJ (or any member of its group) concerning the legal status of any country, territory, jurisdiction or area or of its authorities. This map is provided without any warranty of any kind, either express or implied.

Competing interests None declared.

Patient consent for publication Not required.

Ethics approval Ethical approval was obtained from the Human Research Ethics Committee, The University of Newcastle on 20 March 2018 with reference number H-2018-0066. We also got the Ethiopian Public Health Institute (EPHI) and the Measure DHS programme approval to access the datasets.

Provenance and peer review Not commissioned; externally peer reviewed.

Data availability statement All data relevant to the study are included in the article.

Open access This is an open access article distributed in accordance with the Creative Commons Attribution Non Commercial (CC BY-NC 4.0) license, which permits others to distribute, remix, adapt, build upon this work non-commercially, and license their derivative works on different terms, provided the original work is properly cited, appropriate credit is given, any changes made indicated, and the use is non-commercial. See: http://creativecommons.org/licenses/by-nc/4.0/.

\section{ORCID iD}

Teketo Kassaw Tegegne http://orcid.org/0000-0002-9137-3632

\section{REFERENCES}

1 World Bank. World development indicators. Washington, DC: World Bank, 2009.

2 Darroch JE, Singh S, Nadeau J. Contraception: an investment in lives, health and development. Issues Brief 2008;5:1-4.

3 Cleland J, Bernstein S, Ezeh A, et al. Family planning: the unfinished agenda. Lancet 2006;368:1810-27.

4 Tsui AO, McDonald-Mosley R, Burke AE. Family planning and the burden of unintended pregnancies. Epidemiol Rev 2010;32:152-74.

5 Stover J, Winfrey W. The effects of family planning and other factors on fertility, abortion, miscarriage, and stillbirths in the spectrum model. BMC Public Health 2017;17:775.

6 Bearak J, Popinchalk A, Alkema L, et al. Global, regional, and subregional trends in unintended pregnancy and its outcomes from 1990 to 2014: estimates from a Bayesian hierarchical model. Lancet Glob Health 2018;6:e380-9.

7 Ba DM, Ssentongo P, Agbese E, et al. Prevalence and predictors of contraceptive use among women of reproductive age in 17 sub-Saharan African countries: a large population-based study. Sex Reprod Healthc 2019;21:26-32.

8 Central Statistical Agency (CSA) [Ethiopia], ICF. Ethiopia Demographic and Health Survey 2016. Addis Ababa, Ethiopia, and Rockville, Maryland, USA: CSA and ICF, 2016.

9 Lakew Y, Reda AA, Tamene H, et al. Geographical variation and factors influencing modern contraceptive use among married women in Ethiopia: evidence from a national population based survey. Reprod Health 2013;10:52. 
10 Mandiwa C, Namondwe B, Makwinja A, et al. Factors associated with contraceptive use among young women in Malawi: analysis of the 2015-16 Malawi demographic and health survey data. Contracept Reprod Med 2018;3:12.

11 Shiferaw S, Spigt M, Seme A, et al. Does proximity of women to facilities with better choice of contraceptives affect their contraceptive utilization in rural Ethiopia? PLoS One 2017;12:e0187311.

12 Endriyas M, Eshete A, Mekonnen E, et al. Contraceptive utilization and associated factors among women of reproductive age group in southern nations Nationalities and peoples' region, Ethiopia: cross-sectional survey, mixed-methods. Contracept Reprod Med 2017;2:10.

13 Stephenson R, Hennink M. Barriers to family planning service use among the urban poor in Pakistan. Asia Pac Popul J 2005;19:5-26.

14 Hong R, Montana L, Mishra V. Family planning services quality as a determinant of use of IUD in Egypt. BMC Health Serv Res 2006;6:79.

15 Rose M, Abderrahim N, Stanton C. Maternity care: a comparative report on the availability and use of maternity services. Data from the Demographic and Health Surveys Women's Module \& Services Availability Module 1993-1996. MEASURE Evaluation Technical Report Series No. 9. Carolina Population Center, University of North Carolina at Chapel Hill, 2001.

16 Wang W, Wang S, Pullum T, et al. How family planning supply and the service environment affect contraceptive use: findings from four East African countries. DHS analytical studies no. 26. Calverton, Maryland, USA: ICF International, 2012.

17 Tegegne TK, Chojenta C, Getachew T, et al. Service environment link and false discovery rate correction: methodological considerations in population and health facility surveys. PLoS One 2019;14:e0219860.

18 Burgert C, Zachary B. Incorporating geographic information into demographic and health surveys: a field guide to GPs data collection. Calverton, Maryland USA: ICF International, 2013.

19 Ethiopian Public Health Institute, ICF International. Ethiopia service provision assessment plus (ESPA+) survey 2014. Addis Ababa, Ethiopia and Rockville, Maryland USA: Ethiopian Public Health Institute and ICF International, 2014.

20 Natural Earth. Free vector and raster MAP data. Available: https:// www.naturalearthdata.com/downloads/10m-cultural-vectors/ [Accessed 31 May 2019].

21 Ene M, Leighton EA, Blue GL. Multilevel models for categorical data using SAS® PROC GLIMMIX: the basics. SAS Global Forum 2015 Proceedings, 2015.

22 Tom A, Bosker T, Bosker RJ. Multilevel analysis: an introduction to basic and advanced multilevel modeling. Sage, 1999.

23 Merlo J, Yang M, Chaix B, et al. A brief conceptual tutorial on multilevel analysis in social epidemiology: investigating contextual phenomena in different groups of people. J Epidemiol Community Health 2005;59:729-36.

24 Merlo J, Chaix B, Ohlsson $\mathrm{H}$, et al. A brief conceptual tutorial of multilevel analysis in social epidemiology: using measures of clustering in multilevel logistic regression to investigate contextual phenomena. J Epidemiol Community Health 2006;60:290-7.

25 Goldstein H. Multilevel statistical models. John Wiley \& Sons, 2011.

26 Vrieze SI. Model selection and psychological theory: a discussion of the differences between the Akaike information criterion (AIC) and the Bayesian information criterion (BIC). Psychol Methods 2012;17:228-43.

27 Gagné P, Dayton CM. Best regression model using information criteria. J Mod App Stat Meth 2002;1:479-88.

28 Hirotugu A. A new look at the statistical model identification. IEEE Transactions on Automatic Control 1974;19:716-23.

29 Anselin L. Local Indicators of Spatial Association-LISA. Geogr Anal 1995;27:93-115.

30 Caldas de Castro $\mathrm{M}$, Singer $\mathrm{BH}$. Controlling the false discovery rate: a new application to account for multiple and dependent tests in local statistics of spatial association. Geogr Anal 2006;38:180-208.

31 Central Statistical Authority [Ethiopia]Macro O. Ethiopia demographic and health survey 2000. Addis Ababa, Ethiopia and Calverton, Maryland, USA: Central Statistical Authority and ORC Macro, 2001.

32 Central Statistical Agency [Ethiopia], ORC Macro. Ethiopia demographic and health survey 2005. Addis Ababa, Ethiopia and Calverton, Maryland, USA: Central Statistical Agency and ORC Macro, 2006.

33 Central Statistical Agency [Ethiopia], ICF International. Ethiopia demographic and health survey 2011. Addis Ababa, Ethiopia and Calverton, Maryland, USA: Central Statistical Agency and ICF International, 2012

34 Kebede Y. Contraceptive prevalence in Dembia district, Northwest Ethiopia. Ethiop J Health Dev 2006;20:32-8.

35 Mohammed A, Woldeyohannes D, Feleke A, et al. Determinants of modern contraceptive utilization among married women of reproductive age group in North Shoa zone, Amhara region, Ethiopia. Reprod Health 2014;11:13.

36 Abraham W, Adamu A, Deresse D. The involvement of men in family planning an application of transtheoretical model in Wolaita Soddo town South Ethiopia. Asian J Med Sci 2010;2:44-50.

37 Kamal SMM, Islam MA, Mostafa Kamal S. Contraceptive use: socioeconomic correlates and method choices in rural Bangladesh. Asia Pac J Public Health 2010;22:436-50.

38 Lwelamira J, Mnyamagola G, Msaki M. Knowledge, attitude and practice (KAP) towards modern contraceptives among married women of reproductive age in Mpwapwa district, central Tanzania. Curr Res J Soc Sci 2012;4:235-45. 